\title{
PENGARUH KUALITAS PELAYANAN TERHADAP KEPUASAN KONSUMEN PADA LAYANAN POS EXPRESS PT. POS INDONESIA (PERSERO) KANTOR POS KEDIRI KOTA
}

\author{
Putri Oktaviani; Sasi Utami; Budi Susanto \\ Fakultas Ekonomi - Universitas Kadiri \\ E-mail : sasi@unik-kediri.ac.id
}

\begin{abstract}
Customer satisfaction is an important factor to be influenced by several things, namely the quality of service. The aim to see the partial effect of the quality of its Service on Consumer Satisfaction, knowing the effect of the simultaneous Quality of Service on Customer Satisfaction at PT. Pos Indonesia (Persero) Kediri City Post Office on Jl. Mayjen Sungkono, No.32, Pocanan Kediri East Java. Determination of the sample using incidental techniques and sampling using the Roscoe formula. The results of the study obtained a regression equation $Y=0.122 X 1+0.188 X 2+0.249 X 3+0.138 X 4$ $+0.134 X 5$. There is an influence between Responsiveness partially with the value of $t=$ 2.034 there is the effect of Response Power simultaneously with the value $F=14.555$. Based on the results of the above research, it can be concluded that the significant effect of responsiveness on customer satisfaction at PT. Pos Indonesia (Persero) Kediri City Post Office on Jl. Mayjen Sungkono, No.32, Pocanan Kediri East Java.
\end{abstract}

Keywords: Service Quality, Consumer Satisfaction

\begin{abstract}
ABSTRAK
Kepuasan pelanggan merupakan sesuatu faktor yang penting untuk dipengaruhi beberapa hal yaitu berkualitasnya pelayanan. Tujuan untuk melihat berpengaruh parsial berkualitas Pelayananannya terhadap Kepuasan Konsumen, mengetahuinya pengaruhnya simultan Berkualitasnya Pelayanan terhadap Kepuasan Konsumen di PT. Pos Indonesia (Persero) Kantor Pos Kediri Kota di Jl. Mayjen Sungkono, No.32, Pocanan Kediri Jawa Timur. Penetuan sample menggunakan teknik insidental serta penarikan sampel menggunakan rumus Roscoe. Hasil penelitian diperoleh persamaan regresi $Y=0,122 X_{1}+0,188 X_{2}+0,249 X_{3}+0,138 X_{4}+0,134 X_{5}$. Ada pengaruh antara Daya Tanggap secara parsial dengan nilai $t=2,034$ ada pengaruh Daya Tanggap secara simultan dengan nilai $F=14,555$. Berdasarkan hasil penelitian diatas dapat disimpulkan pengaruh yang signifikan Daya Tanggap terhadap Kepuasan Konsumen pada PT. Pos Indonesia (Persero) Kantor Pos Kediri Kota di Jl. Mayjen Sungkono, No.32, Pocanan Kediri Jawa Timur.
\end{abstract}

Kata Kunci: Kualitas Pelayanan, Kepuasan Konsumen

\section{PENDAHULUAN}

Pada tanggal 25 Februari 1995, POS Indonesia berubah status menjadi Persero.

Dengan berganti status PT. Pos Indonesia kini perusahaan tersebut menjadi mandiri. PT. Pos Indonesia diharapkan dapat memberikan layanan jasa POS yang lebih profesional 
terhadap masyarakat. Saat ini masyarakat semakin sadar bahwa pelayanan publik adalah bagian internal dari masyarakat, karena semua norma nilai dan kepentingan bersama masyarakat harus diperhatikan.PT.Pos Indonesia (Persero) harus berkembang menjadi lebih millenial dalam hal segi pelayanannya agar dapat menjadi tulang punggung logistik e-commerce diIndonesia. (http://www.posindonesia.co.id)

PT. Pos Indonesia (Persero) Kantor Pos Kediri Kota dipilih sebagai objek penelitian tugas akhir penulis, dimana pada jaman yang canggih ini penulis ingin mengetahui bagaimana kepuasan pelanggan di dirasa kurang masimal sehingga pelanggan merasakan suatu ketidakpuasan. Dalam hal ini pengalaman untuk fasilitas di dalam dirasa kurang misalnya parkir yang dirasa cukup memberatkan karena harus membayar. Fasilitas lain dan kurangnya pelayanan antrian yang cukup memakan waktu lama karena antriannya dirasa kurang modern dengan mengambil sendiri dan tidak dibedakan menurut kebutuhan pelanggan misalnya saja seperti mengambil uang, mengambil paket, mengirim barang, membayar langganan listrik maupun air. Penerapan sistem antrian dapat mempermudah dan mempercepat waktu pelayanan karena merupakan suatu hal yang dapat memuaskan konsumen yang datang di PT. Pos Indonesia (Persero) Kantor Pos Kediri Kota. Dengan pelayanan yang baik, akan meningkatkan kepuasan konsumen (Yunanto, 2016)

Fasilitas lain yang kurang adalah tempat ibadah dan toilet itu seharusnya merupakan suatu layanan dasar yang harus dimiliki oleh suatu perusahaan besar (Rahmadi, 2015) seperti PT. Pos Indonesia (Persero) Kantor Pos Kediri Kota karena kurangnya petunjuk akan hal tersebut membuat beberapa konsumen merasa tidak mau berlama-lama untuk antri di sana. Kebersihan merupakan hal yang harus sangat diperhatikan karena menurut penulis beberapa sudut tampak banyak kotoran yang menempel di dinding gedung.

Dengan jumlah pegawai 70 orang dan 11 dibagian pelayanan konsumen dari PT. Pos Indonesia (Persero) Kantor Pos Kediri Kota diharapkan bisa ditingkatkan kualitas pelayanannya agar konsumen puas bisa bersaing atau bahkan melebihi kualitas pelayanan perusahaan lain. Pelayanan yang baik konsumen akan kembali lagi(Satriyono \& Kristanti, 2018) .Beberapa perusahaan lain yang memiliki jasa pengiriman seperti JNE, J\&T expressdirasa sudah cukup modern dalam hal teknologi hal ini menyebabkan persaingan yang sangat ketat dalam hal pengiriman. Keunggulan dari PT. Pos Indonesia 
(Persero) Kantor Pos Kediri Kota yang membedakan dari jasa logistik lain nya adalah sudah berdiri cukup lama dan terpecaya untuk pengiriman surat-surat penting macam BPKB,STNK,KTP dan yang lainnya. Perusahaan tersebut juga mempunyai fasilitas pengiriman uang atau mengambil dana pensiun.

Kesimpulan berdasarkan uraian penelitian mengenai Pengaruh Kualitas Pelayanan Terhadap Kepuasan Konsumen Pada Layanan Pos Express PT. Pos Indonesia (Persero) Kantor Pos Kediri Kota

\section{TINJAUAN PUSTAKA}

\section{Landasan Teori}

\section{Kualitas Jasa}

Menurut Tjiptono (2012:152) dalam (Hari Margono,2010) kualitas jasa adalah hubungan produk dan jasa yang bersumber daya manusia yang kondisinya dinamis di lingkungan yang dapat di harapkan.

Kualitas pelayanan berpusat untuk pemenuhan kebutuhan dan keinginan konsumen juga ketepatan penyampaian untuk mengimbangi harapan konsumen adanya kesesuaian antara pelayanan yang diberikan pelayanan yang dijanjikan dan kesesuaian antara pelayanan yang diterima sesuai dengan harapan dengan konsumen. (Sunyoto, 2012:236)

Pendekatan transendental dipandang sebagai keunggulan bawaan dimana kualitas dapat dirasakan tetapi sulit didefinisikan dan dioperasionalisasikan.

1. Pendekatan berbasis produk menganggap kualitas merupakan karakteristik dapat diukur.

2. Pendekatan berbasis pengguna pemikiran bahwa kualitas tergantung orang yang memandang sehingga produk paling memuaskan preferensi seseorang

3. Pendekatan berbasis manufaktur berdasarkan pasokan secara khusus memperhatikan praktik rekayasa dan manufaktur juga mendefinisikan kualitas sebagai kesesuaian atas kesamaan dan persyaratan.

4. Pendekatan berbasis nilai bersifat relatif sehingga produk bernilai adalah barang atau jasa yang paling tepat untuk dibeli.

\section{Model Kualitas Jasa}


SERVQUAL merupakan model pengukuran gap kualitas pelayanan/jasa (service quality) yang diperkenalkan oleh Vincent Gaspersz. Dalam hal ini kualitas jasa diberikan untuk mempengaruhi kepuasan pelanggan dalam sebuah perusahaan. Tjiptono (2012) kesenjangan yang dapat menyebabkan kegagalan dalam penyampaian jasa kepada pelanggan yang ada antara lain :

1. Knowledge Gap

2. Gap 2 (Standards Gap)

3. Delivery Gap

4. Communications Gap

5. Service Gap

komunikasi gethok tular yang negative, dampak negative terhadap citra korporat dan kehilangan pelanggan.

\section{Strategi Meningkatkan Kualitas Jasa}

Menurut Tjiptono (2012 : 182 - 189) terdapat beberapa faktor yang perlu dipertimbangkan dalam meningkatkan kualitas layanan:

1. Mengidentifikasi determinan utama kualitas layanan

Setiap penyedia layanan diwajibkan untuk menyampaikan layanan berkualitas terbaik kepada konsumen.

2. Mengelola ekspektasi pelanggan

Banyak perusahaan yang berusaha menarik perhatian pelanggan dengan berbagai cara sebagai salah satunya adalah melebih-lebihkan janji sehingga itu menjadi bumerang untuk perusahaan apabila tidak dapat memenuhi apa yang telah dijanjikan.

3. Mengelola bukti kualitas layanan

Pengelolahan ini bertujuan untuk memperkuat penilaian pelanggan selama dan sesudah layanan disampaikan.

4. Mendidik konsumen tentang layanan

Upaya mendidik layanan kepada konsumen bertujuan untuk mewujudkan proses penyampaian dan pengkonsumsian layanan secara efektif dan efisien.

5. Menumbuhkan budaya kualitas

Faktor yang dapat menghambat namun dapat pula memperlancar pengembangan kualitas layanan

6. Menciptakan automating quality 
7. Menindak lanjuti layanan

8. Mengembangkan sistem informasi kualitas layanan

\section{Kepuasan Pelanggan}

Menurut Tjiptono (2014:353) Kepuasan pelanggan adalah respon emosional terhadap pengalaman yang berkaitan dengan produk atau jasa tertentu yang dibeli, gerai ritel, atau bahkan pola perilaku.

Menurut Kotler (2012:150) Satisfaction is a person's feelings of pleasure or dissapointment that result from comparing a product's perceived performance or outcome to expectations. If the performance falls short of expectations, the outcome is dissatisfied. If it matches expectations, the customer is satisfied or delighted.

\section{Manfaat Kepuasan Pelanggan}

Menurut Tjiptono (2012:310) dalam (Tessa utami sutrisno,2015) kepuasan pelanggan memberi manfaat spesifik, diantaranya:

1. Berdampak positif terhadap loyalitas pelanggan

2. Berpotensi jadi sumber pendapatan masa depan

3. Menekan biaya transaksi pelanggan masa depan, terutama biaya komunikasi pemasaran, penjualan, dan layanan pelanggan

4. Meningkatkan toleransi harga utamanya kesediaan pelanggan membayar harga premium dan pelanggan cenderung tidak mudah tergoda untuk beralih pemasok

5. Menumbuhkan rekomendasi yang menular secara positif

6. Meningkatkan bargaining power relative perusahaan terhadap jaringan pemasok, mitra bisnis, dan saluran distribusi

\section{Metode Pengukuran Kepuasan Pelanggan}

Menurut Fandy Tjiptono (2012:320) dalam (Ida Manullang, 2008) pengukuran kepuasan dilakukan tujuannya:

1. Mengidentifikasi keperluan pelanggan

2. Menentukan tingkat kepuasan pelanggan terhadap kinerja organisasi pada aspek penting.

3. Membandingkan tingkat kepuasan pelanggan terhadap perusahaan dengan tingkat kepuasan pelanggan terhadap organisasi baik dengan pesaing langsung maupun pesaing tidak langsung. 
4. Mengidentifikasi Priorities for Improvement melalui analisa gap antara skor tingkat kepentingan dan kepuasan.

5. Mengukur indeks kepuasan pelanggan yang menjadi indikator dalam memantau kemajuan perkembangan waktu kewaktu.

\section{Hubungan Kualitas Jasa dengan Kepuasan Pelanggan}

Tjiptono (2014:295) dalam (Satriyono \& Ruhamak, 2017) tentang hubungan kualitas jasa dan kepuasan konsumen yaitu :

1. Jika konsumen tidak memiliki pengalaman pada suatu perusahaan maka persepsinya terhadap kualitas jasa perusahaan tersebut akan didasarkan pada ekspektasinya.

2. Interaksi berikutnya dengan perusahaan tersebut akan menyebabkan konsumen memasuki proses dikonfirmasi dan merevisi persepsinya terhadap kualitas jasa.

3. Setiap interaksi akan memperkuat persepsi atau sebaliknya malah persepsi pelanggan terhadap kualitas jasa.

4. Persepsi terhadap kualitas jasa telah direvisi memodifikasi minat beli konsumen terhadap pembelian di masa datang.

\section{Kerangka Berpikir}

Gambar 1. Kerangka Berpikir

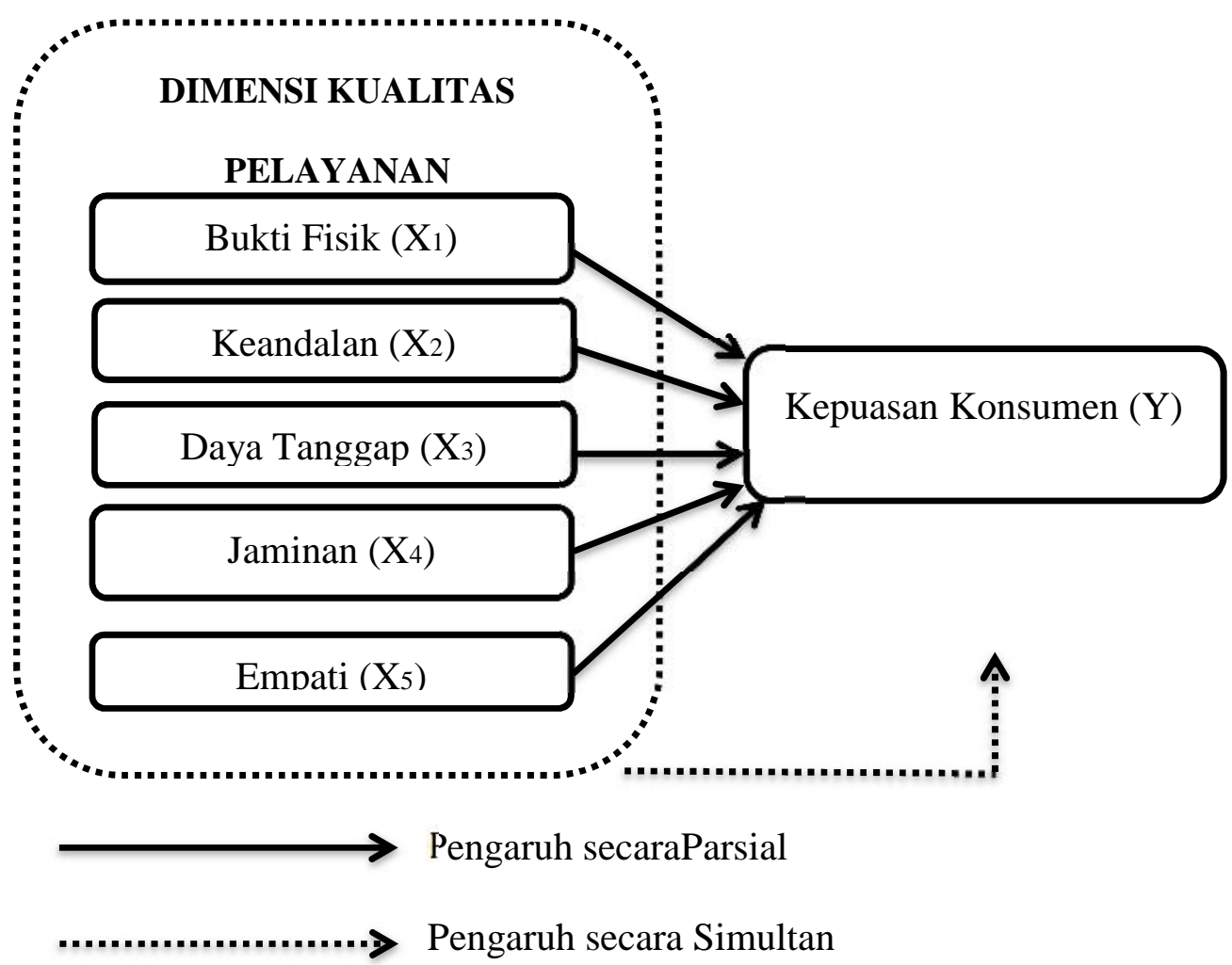

Sumber: Tjiptono (2012) 


\section{Hipotesis}

H1. Terdapat pengaruh secara parsial kualitas pelayanan terdiri bukti fisik, keandalan, daya tanggap, jaminan dan empati terhadap kepuasaan konsumen

H2. Terdapat pengaruh secara simultan antara kualitas pelayanan yang terdiri bukti fisik, keandalan, daya tanggap, jaminan dan empati terhadap kepuasan konsumen

H3. Terdapat pengaruh kualitas pelayanan yang paling dominan bukti fisik kepuasan konsumen

\section{METODE PENELITIAN}

\section{Populasi}

Peneliti mengambil populasi dalam kurun waktu 1 hari.

\section{Sampel}

Sampel pada penelitian ini diambil dari populasi sesuai dengan kriteria, yaitu konsumen jasa Pos Express PT. Pos Indonesia Kantor Pos Kediri.Teknik yang diambil adalah Accidental sampling. Berdasarkan perhitungan yang peneliti lakukan maka jumlah sampel yaitu 60 .

\section{Metode Pengambilan Sampel}

Penelitian ini menggunakan teknik sampling insidental.

\section{Variabel Penelitian, Cara Pengukuran dan Definisi Operasional Variabel Penelitian}

1. Variabel Independen (X)

2. Variabel Dependen (Y)

\section{Cara Pengukuran}

Sangat setuju skor 5, Setuju dengan skor 4, Netral dengan skor 3, Tidak setuju dengan skor 2, Sangat tidak setuju dengan skor 1

\section{Definisi Operasional}

\section{Tabel 1. Definisi Operasional}

\begin{tabular}{|c|c|c|}
\hline Konsep & Variabel & Indikator \\
\hline $\begin{array}{ll}\text { Dimensi } & \text { Kualitas } \\
\text { Pelayanan } & \end{array}$ & Bukti Fisik (X1) & $\begin{array}{l}\text { Tampilan Fisik. Item: } \\
\text { - Penampilan fisik gedung } \\
\text { - Peralatan dan teknologi yang dimiliki } \\
\text { kantor pos. } \\
\text { - Penampilan karyawan rapi }\end{array}$ \\
\hline
\end{tabular}




\begin{tabular}{|c|c|c|}
\hline & & 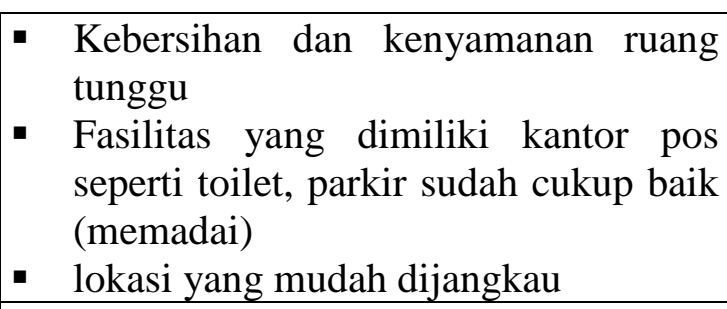 \\
\hline & Keandalan (X2) & $\begin{array}{l}\text { Kemampuan pelayanan dengan tepat. } \\
\text { Item: } \\
\text { - Sambutan baik karyawan kepada } \\
\text { konsumen } \\
\text { - Penyampaian layanan baik } \\
\text { - Bersikap simpatik }\end{array}$ \\
\hline & Daya Tanggap (X3) & $\begin{array}{l}\text { Kemampuan Membantu Konsumen. } \\
\text { Item: } \\
\text { - Layanan yang cepat dan tepat } \\
\text { - Selalu tanggap membantu konsumen } \\
\text { - Memberikan tanggapan positif jika } \\
\text { konsumen mengajukan klaim } \\
\text { - Memberikan informasi yang jelas } \\
\text { kepada konsumen }\end{array}$ \\
\hline & Jaminan (X4) & $\begin{array}{l}\text { Pengetahuan dan kesopanan karyawan, } \\
\text { keamanan barang kiriman. Item: } \\
\text { - Garansi ganti rugi } \\
\text { - Karyawan menguasai jasa perposan } \\
\text { dan produk } \\
\text { - Karyawan bersikap ramah }\end{array}$ \\
\hline & Empati (X5) & $\begin{array}{l}\text { Kepedulian Terhadap Konsumen. Item: } \\
\text { - Karyawan tanggap } \\
\text { - Karyawan bersabar } \\
\text { menghadapi konsumen } \\
\text { - Karyawan memberikan perhatian } \\
\text { kepada setiap konsumen } \\
\text { Karyawan memberikan solusi dari } \\
\text { masalah }\end{array}$ \\
\hline $\begin{array}{l}\text { Kepuasan } \\
\text { Konsumen }\end{array}$ & $\begin{array}{l}\text { Kepedulian } \\
\text { terhadap konsumen }\end{array}$ & $\begin{array}{l}\text { Tanggapan Konsumen. Item: } \\
\text { - Konsumen merasa puas terhadap } \\
\text { pelayanan Kantor Pos Kediri } \\
\text { - Konsumen merekomendasikan Kantor } \\
\text { Pos Kediri ke orang lain } \\
\text { - Selalu menggunakan jasa pengiriman } \\
\text { barang dengan Kantor Pos Kediri . }\end{array}$ \\
\hline
\end{tabular}

\section{Metode Pengumpulan Data}
a. Metode Observasi
b. Metode Wawancara 
c. Metode Kuesioner

\section{Jenis Data}

1. Data primer

2. Data sekunder

\section{Teknik Pengukuran Data}

\section{Uji Instrumen Data}

1. Uji Validitas

2. Uji Reliabilitas

\section{Metode Analisis Data}

Pengolahan data merupakan suatu langkah penting dalam suatu penelitian.

\section{Analisis Deskriptif}

Menurut Sugiyono (2014:206) dalam (Vidya Metayunika,2013) analisis deskriptif yaitu statistik untuk menganalisis data telah terkumpul sebagai kesimpulan yang berlaku umum atau generalisasi.

\section{Analisis Regresi Linier Berganda}

Teknik ini menggunakan program SPSS Statistic

$$
\mathrm{Y}=\mathrm{a}+\mathrm{b}_{1} X_{1}+b_{2} X_{2}+b_{3} X_{3}+b_{4} X_{4}+b_{5} X_{5}+
$$

Keterangan:

$\begin{array}{llll}\mathrm{Y} & =\text { Kepuasan Konsumen } & X_{3} & =\text { Daya tanggap } \\ \mathrm{a} & =\text { Koefisien konstanta } & X_{4} & =\text { Jaminan } \\ b_{1}, b_{2}, b_{3}, \ldots & =\text { Koefisien regresi } & X_{5} & =\text { Empati } \\ X_{1} & =\text { Bukti Fisik } & & =\text { Variabel gangguan } \\ X_{2} & =\text { Keandalan } & \end{array}$

\section{Uji Simultan (Uji F)}

Uji F dengan uji parameter $\beta$ (uji korelasi) menggunakan uji F-statistik.pengaruh variabel bebas secara bersama-sama terhadap variabel terikat digunakan uji F. Menurut Sugiyono (2013:257) dirumuskan sebagai berikut:

$$
F=\frac{(R 2 / K)}{(1-R 2 / n-k-1)}
$$

Keterangan : 
$\mathrm{F} \quad=\mathrm{F}_{\text {hitung }}$ yang selanjutnya akan dibandingkan dengan $\mathrm{F}_{\text {tabel }}$

R2 = Koesioner determinasi

$\mathrm{n} \quad=$ Jumlah sampelkaidah pengujian signifikan : jika $\mathrm{F}_{\text {hitung }}$ probabilitas $<0,05$, maka , $\mathrm{H}_{0}$ ditolak .

\section{Uji Parsial (Uji t)}

Uji t menggunakan signifikan level 0,05 ( $\alpha=5 \%)$. Diterima atau ditolak hipotesis kriteria: 1. Jika nilai signifikan > 0,05 maka hipotesis ditolak. Secara parsial variabel independen tidak mempunyai pengaruh secara signifikan terhadap variabel dependen. Jika nilai signifikan $\leq 0,05$ maka hipotesis diterima.secara parsial variabel independen tersebut mempunyai pengaruh yang signifikan terhadap variabel dependen.

\section{HASIL PENELITIAN DAN PEMBAHASAN}

\section{Hasil Penelitian}

PT. Pos Indonesia (Persero) mempunyai 3.700 Kantor Pos online yang ada di Indonesia,kantor pos cabangnya adalah Kantor Pos Kediri yang berada di Jalan Mayjend Sungkono No. 32 Kota Kediri, Jawa Timur. Kantor Pos Kediri mempunyai 8 loket jam kerja Hari Senin - Kamis pukul 07.00 WIB - 22.00 WIB dan Hari Jumat Sabtu 07.00 WIB - 21.00 WIB. Kantor Pos Cabang Kediri membawahi 29 kantor pos pembantu di kota dan kabupaten Kediri.

\section{Spesifikasi Produk}

Kantor Pos suatu perusahaan dibidang jasa yang ditawarkan sebagai berikut: Filateli dan konsinyasi (prangko dan meterai), AdmailPos, Express Mail Service (EMS) dan RLN internasional, Pos Ekspor, Paket Pos (Biasa, Kilat, Kilat Khusus, Ekspres,Jumbo), Surat Pos (Biasa, Kilat, Kilat Khusus, Ekspres), Logistik, Kargo, Bank Channeling, Fund Distribution (Western Union dan PosPay), Giro Pos, Wesel Pos, Gallery Pos, PostShop, Pos Niaga (ditiadakan), Agen Pos.

\section{Lokasi Penelitian}

Penelitian ini dilakukan diPT. Pos Indonesia (Persero) Kantor Pos Kediri Kota yang terletak di Jalan Meyjen Sungkono No. 32 Kota Kediri

\section{Waktu Penelitian}

Penelitian dilakukan pada tanggal 9 Januari 2018 dengan melakukan penyebaran angket koesioner secara random sampling. 


\section{Hasil Penelitian}

Sampel penelitian ini adalah 60 orang berdasarkan jenis kelamin, usia, frekuensi penggunaan jasa .

Tabel 2. Responden Jenis Kelamin

\begin{tabular}{|l|c|c|}
\hline $\begin{array}{c}\text { Jenis Kelamin } \\
\text { Responden }\end{array}$ & $\begin{array}{c}\text { Jumlah Reponden } \\
\text { (Orang) }\end{array}$ & $\begin{array}{c}\text { Presentase } \\
(\mathbf{\%})\end{array}$ \\
\hline Laki - Laki & $\mathbf{3 1}$ & $\mathbf{5 1 , 7 \%}$ \\
\hline Perempuan & $\mathbf{2 9}$ & $\mathbf{4 8 . 3 \%}$ \\
\hline Total & $\mathbf{6 0}$ & $\mathbf{1 0 0 \%}$ \\
\hline
\end{tabular}

Sumber Data Primer Yang Diolah (2018)

Jumlah responden sebanyak 60 orang terdiri dari 51,7\% Laki - laki dan Perempuan $48,3 \%$.

Tabel 3. Responden Berdasarkan Usia

\begin{tabular}{|c|c|c|}
\hline $\begin{array}{c}\text { Usia Responden } \\
\text { (Tahun) }\end{array}$ & $\begin{array}{c}\text { Jumlah Responden } \\
\text { (Orang) }\end{array}$ & $\begin{array}{c}\text { Presentasi } \\
(\mathbf{\%})\end{array}$ \\
\hline$<20$ tahun & 7 & $11,7 \%$ \\
\hline $21-30$ tahun & 25 & $41,6 \%$ \\
\hline $31-40$ tahun & 12 & $20 \%$ \\
\hline $41-50$ Tahun & 9 & $15 \%$ \\
\hline$>51$ Tahun & 7 & $11,7 \%$ \\
\hline
\end{tabular}

Sumber: Data Primer Yang Diolah (2018)

Responden dengan usia 21-30 Tahun menempati prosentase tertinggi yaitu sebesar 41,6\% di ikuti dengan responden dengan umur 31-40 sebesar 20\%.

\section{Uji Validitas}

Tabel 4. Bukti Fisik (X1)

\begin{tabular}{|c|c|c|}
\hline X1 & R hitung & R tabel \\
\hline $\mathrm{X} 1.1$ & 751 & 0,254 \\
\hline $\mathrm{X} 1.2$ & 672 & 0,254 \\
\hline $\mathrm{X} 1.3$ & 660 & 0,254 \\
\hline $\mathrm{X} 1.4$ & 672 & 0,254 \\
\hline $\mathrm{X} 1.5$ & 723 & 0,254 \\
\hline
\end{tabular}

Berdasarkan uji validitas, diketahui seluruh pertanyaan dari variabel bukti fisik mempunyai nilai $\mathrm{r}$ hitung $>\mathrm{r}$ tabel, berarti seluruh pertanyaan seluruhnya Valid digunakan dalam penelitian.

Tabel 5. Keandalan (X2)

\begin{tabular}{|l|l|l|}
\hline X2 & R hitung & R tabel \\
\hline
\end{tabular}




\begin{tabular}{|l|l|l|}
\hline $\mathrm{X} 2.1$ & 662 & 0,254 \\
\hline $\mathrm{X} 2.2$ & 672 & 0,254 \\
\hline $\mathrm{X} 2.3$ & 641 & 0,254 \\
\hline
\end{tabular}

Berdasarkan uji validitas, diketahui seluruh pertanyaan dari variabel keandalan nilai $\mathrm{r}$ hitung > dari $\mathrm{r}$ tabel, berarti seluruh pertanyaan seluruhnya Valid digunakan dalam penelitian.

Tabel 6. Daya Tanggap (X3)

\begin{tabular}{|c|c|c|}
\hline X3 & R hitung & R tabel \\
\hline X3.1 & 730 & 0,254 \\
\hline X3.2 & 833 & 0,254 \\
\hline X3.3 & 776 & 0,254 \\
\hline X3.4 & 685 & 0,254 \\
\hline
\end{tabular}

Berdasarkan uji validitas, diketahui seluruh pertanyaan dari variabel daya tanggap mempunyai nilai $r$ hitung $>$ dari $r$ tabel,berarti seluruh pertanyaan seluruhnya Valid digunakan dalam penelitian.

Tabel 7. Jaminan (X4)

\begin{tabular}{|c|c|c|}
\hline X4 & R hitung & R tabel \\
\hline $\mathrm{X} 4.1$ & 655 & 0,254 \\
\hline $\mathrm{X} 4.2$ & 737 & 0,254 \\
\hline $\mathrm{X} 4.3$ & 752 & 0,254 \\
\hline $\mathrm{X} 4.4$ & 842 & 0,254 \\
\hline $\mathrm{X} 4.5$ & 710 & 0,254 \\
\hline
\end{tabular}

Berdasarkan uji validitas, diketahui seluruh pertanyaan dari variabel jaminan mempunyai nilai $\mathrm{r}$ hitung > dari $\mathrm{r}$ tabel, berarti seluruh pertanyaan seluruhnya Valid dapat digunakan dalam penelitian.

Tabel 8. Empati X5

\begin{tabular}{|c|c|c|}
\hline X5 & R hitung & R tabel \\
\hline X5.1 & 770 & 0,254 \\
\hline X5.2 & 811 & 0,254 \\
\hline X5.3 & 822 & 0,254 \\
\hline X5.4 & 846 & 0,254 \\
\hline
\end{tabular}

Berdasarkan uji validitas, diketahui seluruh item pertanyaan dari variabel empati nilai $\mathrm{r}$ hitung $>$ dari $\mathrm{r}$ tabel, berarti seluruh item pertanyaan tersebut seluruhnya Valid dan dapat digunakan dalam penelitian.

Tabel 9. Kepuasan Konsumen $Y$

\begin{tabular}{|c|c|c|}
\hline Y & R hitung & R tabel \\
\hline Y.1 & 797 & 0,254 \\
\hline
\end{tabular}




\begin{tabular}{|l|l|l|}
\hline Y.2 & 839 & 0,254 \\
\hline Y.3 & 841 & 0,254 \\
\hline
\end{tabular}

Berdasarkan uji validitas, diketahui seluruh pertanyaan dari variabel kepuasan konsumen mempunyai nilai $\mathrm{r}$ hitung > dari $\mathrm{r}$ tabel sesuai ketentuan yang ditetapkan, pertanyaan tersebut seluruhnya Valid dan dapat digunakan penelitian.

\section{Uji Reliabilitas}

Uji reliabilitas variabel antara variabel Bukti Fisik, Keandalan, Daya Tanggap, Jaminan, Empati, Kepuasan Konsumen diperoleh nilai Cronbach's Alpha> 60. Dapat disimpulkan bahwa koesioner yang peneliti gunakan dalam penelitian ini sudah sangat dipercaya .

\section{Uji Regresi Linier Berganda}

Persamaan diatas dapat diinterpretasikan sebagai berikut:

1. Variabel bukti fisik (X1) memiliki koefisien sebesar 0,144 dengan tanda positif

2. Variabel keandalan (X2) memiliki koefisien sebesar 0,122 dengan tanda posisti

3. Variabel daya tanggap (X3) memiliki koefisien sebesar 0,249 dengan tanda posistif.

4. Variabel jaminan (X4) memiliki koefisien sebesar 0,138 dengan tanda posistif.

5. Variabel empati (X5) memiliki koefisien sebesar 0,134 dengan tanda posistif.

Dari persamaan regresi di atas dapat kita lihat bahwa nilai koefisien b4 memiliki nilai koefisien yang lebih besar dibandingkan dengan nilai koefisien yang dimiliki oleh b1, b2, b3, b4, dan b5. variabel jaminan (X4) variabel yang memiliki pengaruh dominan terhadap variabel kepuasan konsumen (Y).

\section{Uji t}

Uji t X3 berpengaruh secara parsial terhadap kepuasan konsumen. Sedangkan $\mathrm{X} 1, \mathrm{X} 2, \mathrm{X} 4, \mathrm{X} 5$ tidak berpengaruh terhadap kepuasan konsumen.

\section{Uji F}

Uji F yang dilakukan, diperoleh nilai Fhiitung sebesar 14,555 dengan tingkat signifikan, $000^{\text {b }}$. Karena tingkat signifikan jauh lebih kecil dari 0.5, disimpulkan X1, X2, $\mathrm{X} 3, \mathrm{X} 4, \mathrm{X} 5$ secara simultan terhadap kepuasan konsumen.

\section{Uji Validitas}

Uji Validitas digunakan untuk mengukur: Bukti Fisik (X1), Keandalan (X2),Daya Tanggap (X3),Jaminan (X4),Empati (X5),Kepuasan Kosumen (Y) 


\section{Uji Reliabilitas}

Uji reliabilitas variabel antara variabel Bukti Fisik, Keandalan, Daya Tanggap, Jaminan, Empati, Kepuasan Konsumen diperoleh nilai Cronbach's Alpha> 60.Bahwa koesioner yang peneliti gunakan dalam penelitian ini sudah sangat yakin .

\section{Uji Regresi Linier Berganda}

Teknik diatas dilakukan menggunakan program SPSS Statistic

$$
\mathrm{Y}=\mathrm{a}+\mathrm{b}_{1} X_{1}+b_{2} X_{2}+b_{3} X_{3}+b_{4} X_{4}+b_{5} X_{5}+
$$

Keterangan:

$$
\begin{array}{lll}
\mathrm{Y} & =\text { Kepuasan Konsumen } & X_{3}=\text { Daya tanggap } \\
\mathrm{a} & =\text { Koefisien konstanta } & X_{4}=\text { Jaminan } \\
b_{1}, b_{2}, b_{3}, \ldots & =\text { Koefisien regresi } & X_{5}=\text { Empati } \\
X_{1} & =\text { Bukti Fisik } & =\text { Error, variabel gangguan } \\
X_{2} & =\text { Keandalan } &
\end{array}
$$

\section{Uji t}

Pengujian dilakukan dengan menggunakan signifikan level $0,05 \quad(\alpha=5 \%)$. Penerimaan atau penolakan hipotesis dilakukan dengan kriteria: 1. Jika nilai signifikan $>0,05$ maka hipotesis ditolak. Jika nilai signifikan $\leq 0,05$ maka hipotesis diterima.secara parsial variabel independen mempunyai pengaruh signifikan terhadap variabel dependen.

Hasil uji t dapat disimpulkan X3 berpengaruh secara parsial terhadap kepuasan konsumen. Sedangkan X1, X2,X4,X5 tidak pengaruh terhadap kepuasan konsumen.

\section{Uji F}

$$
F=\frac{(R 2 / K)}{(1-R 2 / n-k-1)}
$$

Keterangan :

$\mathrm{F}=\mathrm{F}_{\text {hitung }}$ yang selanjutnya akan dibandingkan dengan $\mathrm{F}_{\text {tabel }}$

R2 = Koesioner determinasi

$\mathrm{n} \quad=$ Jumlah sampelkaidah pengujian signifikan : jika $F_{\text {hitung }}>F_{\text {tabel }}$ dan nilai 
probabilitas $<0,05$, maka , $\mathrm{H}_{0}$ ditolak (signifikan).

Hasil uji $\mathrm{F}$ yang dilakukan, diperoleh nilai $\mathrm{F}_{\text {hitung }}$ sebesar 14,555 dengan tingkat signifikan, $000^{\mathrm{b}}$. Karena tingkat signifikan jauh lebih kecil dari 0.5, disimpulkan bahwa $\mathrm{X} 1, \mathrm{X} 2, \mathrm{X} 3, \mathrm{X} 4, \mathrm{X} 5$ berpengaruh secara simultan terhadap kepuasan konsumen.

\section{Pembahasan}

Dari hasil analisis variabel kualitas pelayanan dan kepuasan konsumen pada PT. Pos indonesia (persero) kantor pos kediri kota mempunyai pengaruh signifikan terhadap kepuasan konsumen dibuktikan hasil uji analisis regresi. Hasil penelitian didukung penelitian terdahulu oleh Ayu Titisari dengan judul Pengaruh Kualitas Pelayanan Dan Kualitas Produk Terhadap Kepuasan Pelanggan PT.Pos Indonesia (Persero) yang menyatakan bahwa kualitas pelayanan dan kualitas produk memiliki pengaruh sebesar 24,8\% dan signifikan terhadap kepuasan pelanggan PT.Pos Indonesia (Persero). Selain kualitas pelayanan dan kualitas produk penelitian oleh Suci Wulansari dengan judul Analisis Pengaruh Kualitas Pelayanan, Harga Dan Lokasi Terhadap Kepuasan Pelanggan Pada Bengkel AHASS MPM Motor Kediri hasil penelitian membuktikan pengaruh antara pelayanan terhadap kepuasan pelanggan melalui hasil perhitungan telah dilakukan di AHAS MPM Motor Kediri. Dengan demikian Kualitas Pelayanan memiliki pengaruh terhadap kepuasan pelanggan.untuk menjamin kepuasan pelanggan dapat terwujud dilakukan oleh PT. Pos Indonesia (Persero) Kantor Pos Kediri Kota yaitu menjamin kualitas pelayanan untuk tetep baik.

\section{KESIMPULAN DAN SARAN}

\section{Kesimpulan}

Analisis data dapat ditarik kesimpulan:

1. Hasil analisis $\mathrm{t}$ tset yang menunjukkan bahwa $\mathrm{t}$ hitung $=1,293$ dengan nilai sig $0,202<0,05$.

2. Hasil analisis t test yang menunjukkan bahwa t hitung $=1,518$ dengan nilai sig $0,135<0,05$.

3. Hasil analisis t test yang menunjukkan bahwa t hitung $=2,034$ dengan nilai sig $0,047<0,05$.

4. Hasil analisis $t$ test yang menunjukkan bahwa $t$ hitung $=1,659$ dengan nilai sig $0,103<0,05$. 
5. Hasil analisis $\mathrm{t}$ test yang menunjukkan bahwa $\mathrm{t}$ hitung $=1,253$ dengan nilai sig $0,216<0,05$.

6. Hasil analisis $\mathrm{F}$ test yang meunjukkan bahwa Fhitung $=14,555$ dengan sig 0,000 $<0,05$.

\section{Saran}

1. Variabel kualitas pelayanan terdiri Bukti Fisik, Keandalan, Daya Tanggap, Jaminan, Empati memiliki pengaruh terhadap kepuasan konsumen (Y) Kantor Pos Kota Kediri, maka hendaknya Kantor Pos Kota Kediri memperhatikan kelima variabel kualitas pelayanan tersebut dalam melakukan kebijakan pemasaran dan dalam memutuskan kebijakan yang berhubungan dengan konsumen yang optimal.

2. Kualitas pelayanan Bukti fisik, Keandalan, Daya Tanggap, Jaminan, dan Empati Kantor Pos Kota Kediri juga harus memperhatikan kepuasan konsumen.

3. Kantor Pos kota Kediri harus terus meningkatkan kualitas pelayanan dan harus bisa bersaing dengan perusahan pesaing yang juga menawarkan jasa yang sama dengan Kantor Pos Kota Kediri.

\section{DAFTAR PUSTAKA}

Alma, Buchari. 2013. Manajemen Pemasaran dan Pemasaran Jasa. Alfabeta: Bandung. Falakh adhhy Fajrur nur. 2016. https://docplayer.info/54739527Analisis pengaruh harga pelayanan fasilitas dan lokasi terhadap kepuasan pelanggan di hotel bintang tawangmangu.html

Manullang, Ida. 2008. http://blog.umy.ac.id/ghea/files/2011/12/pengaruh kualitas pelayanan terhadap kepuasan pelanggan jasa penerbangan PT. Garuda IndonesiaAirline-di-bandara-Polonia-Medan.pdf

Metayunika,Vidya. 2013. http://eprints.undip.ac.id/39615/1/METAYUNIKA.pdf

Margono, Hari. 2010. Hubungan antara bukti dengan tingkat kepuasan pemakai jasa perpustakaan universitas sanata dharma kampus 1 mrican .https://repository.usd.ac.id/14151/2/042214081_Full.pdf

Kotler. 2012. Principles of Marketing. 14 Edition. Pearson Education: United States of America.

Kotler, Philip and Keller, Kevin Lane. 2013. Manajemen Pemasaran, Jilid 1, Edisi 13, Erlangga.

Lupiyoadi, Rambat. 2014. Manajemen Pemasaran Jasa Berbasis Kompetensi. Edisi ke3. Salemba Empat: Jakarta.

Nita. http://repository.unpas.ac.id/5617/6/BAB\%20III\%20nita\%20-\% 20revisi.pdf

Priyatno, Duwi. 2013. Mandiri Belajar Analisis Data Dengan SPSS. Mediakom: Yogyakarta.

Sangadji, E.M., dan Sopiah. 2013. Prilaku Konsumen: Pendekatan Praktis Disertai: Himpunan Jurnal Penelitian. Penerbit Andi: Yogyakarta.

Sugiyono. 2012. Metodologi Penelitian Pendidikan Pendekatan Kuantitatif, Kualitatif 
dan $R \& D$. Alfabeta: Bandung.

Sugiyono. 2013. Statistika Untuk Penelitian. Alfabeta: Bandung.

Sugiyono. 2014. Metode Penelitian Pendidikan Pendekatan Kuantitatif, Kualitatif Dan $R \& D$. Alfabeta: Bandung.

Sunyoto, D. 2012. Manajemen Sumber Daya Manusia. CAPS: Yogyakarta.

Rahmadi, A. N. (2015). ANALISIS KUALITAS PELAYANAN, KUALITAS PRODUK DAN KENYAMANAN TERHADAP KEPUTUSAN KONSUMEN DALAM MENGGUNAKAN JASA SPORT CENTER (Studi Kasus Mensana Sport Center Futsal Kediri). Jurnal Kompilasi Ilmu Ekonomi (KOMPILEK), 7(1), 37-45.

Satriyono, G., \& Kristanti, D. (2018). Pengaruh kepuasan pasien pada kualitas layanan Rawat Inap terhadap niat Discharge Against Medical Advice ( DAMA ) ( Studi di Rumah Sakit Umum Daerah Pare Kabupaten Kediri ). Ekonika, 3(2), 136-153. https://doi.org/https://doi.org/10.30737/ekonika.v3i2.190

Satriyono, G., \& Ruhamak, M. D. (2017). ANALISIS KESENJANGAN ANTARA EKSPEKTASI KONSUMEN TERHADAP PERSEPSI JASA PELAYANAN (Studi Kasus pada Bengkel Cat dan Las Mobil Warna Indah di Kediri). EkoNiKa Jurnal Ekonomi Universitas Kadiri, 2(2), 127-141.

https://doi.org/http://dx.doi.org/10.30737/ekonika.v2i2.39

Yunanto, Y. (2016). ANALISIS PENGARUH KUALITAS PELAYANAN DAN DISIPLIN KERJA KARYAWAN TERHADAP KEPUASAN PASIEN ASKES DI PT ASKES KEDIRI. Jurnal Ekonomi Universitas Kadiri, 1(1), 26-37. 